\title{
Research on the Financing of Corporate Equity Pledge in the OTC Market
}

\author{
Fangyun Dou

\begin{abstract}
School of Economics, Finance and Management, University of Bristol, Bristol BS8 1TL, Britain
\end{abstract} \\ *Corresponding author. Email: dfydoudou@163.com
}

\begin{abstract}
In recent years, equity pledge financing has developed rapidly in the NEEQ. In 2017, the number of equity pledges in NEEQ reached a new high. After a company joins the NEEQ, its information disclosure has been strengthened, management has become more standardized, the liquidity of enterprises' shares has been enhanced, and equity pricing has been fairly evaluated. Therefore, equity pledge financing has important practical significance for these companies in the development.

This paper takes Xinwei Science and Technology as an example to analyze and study its equity pledge financing mode. Firstly, the article gives a general introduction to the NEEQ, mainly focusing on the development and financing situation of the NEEQ. Then it analyses the basic situation and financing situation of Xinwei Science and Technology. From the aspects of financing mode, rationality, feasibility, effect and risk of equity pledge financing, it finds that equity pledge financing is comparable to other financing parties. The advantages of this model can provide some references for the future improvement and development of equity pledge financing function in NEEQ.
\end{abstract}

Keywords: NEEQ, Equity pledge financing, SME

\section{INTRODUCTION}

Compared with listed companies, small and medium-sized enterprises have the disadvantages of limited capital scale and low degree of information disclosure. Therefore, when small and medium-sized enterprises apply for loans from banks, banks need to bear higher risks. Therefore, small and medium-sized enterprises often need to pay higher cost. In addition to bank loans, some small and medium-sized enterprises also choose to issue bonds to raise the funds they need. However, due to the high threshold for issuing bonds, only a few companies can meet the standards to successfully issue and raise funds, and most companies still face financing difficulties and expensive financing.

Since the establishment of the NEEQ, through the continuous improvement of the institutional framework and transaction mechanism, the management quality and information disclosure level of listed companies have been significantly improved. Small and medium-sized enterprises can meet their liquidity requirements by listing on the NEEQ. The traditional financing method of NEEQ companies is targeted issuance, but after the fixed increase in financing reached the peak in 2016, the amount raised in 2017 and 2018 showed a significant decline, resulting in a considerable number of companies unable to raise funds Required funds. Therefore, more and more small and medium-sized enterprises are participating in equity pledge financing. The amount of equity pledge financing has been rising in recent years, and it has surpassed the private placement in 2016, which has made up for the company's funding gap. It can be speculated that equity pledge financing will play an increasingly important role in the future.

\section{RESEARCH STATUS}

\subsection{SME financing theory}

Chen Can (2016) pointed out that China's large state-owned banks generally prefer to extend loans to large state-owned enterprises and ignore small and medium-sized enterprises in general. Therefore, the bank loan mechanism cannot meet the needs of small and medium-sized enterprises for funds, mainly because these enterprises themselves and the credit level and the scale of development did not meet the requirements of banks for lending. As a result, the banks have high lending costs and strict procedures, and the scale of lending is ultimately limited. There are also many 
scholars who have done different researches on how to solve this dilemma and have all put forward their own views. [1] Liu Quanyue (2017) believes that it is possible to innovate and develop a credit model suitable for small and medium-sized enterprises to solve this gap problem [2]; Zhang Nan (2018) believes that solving this gap problem requires two aspects Coordination, on the one hand, is the improvement of the overall market background. The financial system and capital market should make corresponding innovations to adapt to the new situation. Affordability [3]; Gao Mingzhe (2016) proposed that the national share transfer system can play a special role in solving the financing difficulties of SMEs. [4]

\subsection{The theory of corporate financing structure}

According to the MM theorem, under the premise of the perfect market assumption, corporate value and cost of capital have nothing to do with capital structure. Under the premise of relaxing tax assumptions, due to the tax shield effect of liabilities, the more debts, the smaller the corporate cost of capital, the value of the company will be higher. Subsequently, the trade-off theory was further developed on the basis of the MM theory. The trade-off theory balances the cost brought by debt and the income generated by tax saving, and comprehensively considers the cost of financial distress, bankruptcy cost, and tax shield effect. Choose the best capital structure. The optimal financing theory relaxes the assumption of information symmetry in the tax-free MM theory, and believes that only the managers of the enterprise can fully grasp the full information about the enterprise, and the investor's understanding of the enterprise information is asymmetrical, and it is necessary to observe the enterprise's behavior of the company to judge the situation of the company. Issuing new shares will make investors believe that the current company's stock price is overvalued. Therefore, equity financing may send negative information to the market. Under the support of this theory, companies should follow a certain order when financing: First, seek financing channels internally and then externally, and external financing should follow the order of debt financing first and equity financing. Then he developed the financial growth cycle theory. This theory believes that the financing sequence of a company should not remain unchanged. Depending on the stage, the selected financing sequence will be different. The initial stage of the enterprise is small due to its small scale. There is little business, so it is more difficult to obtain external financing; companies in the growth period can mortgage or pledge their assets to financial institutions for financing; companies in the mature period can choose to raise funds in the capital market. [5]

\subsection{OTC market financing function}

China's over-the-counter market is still in the early stages of development, so the theory on the financing function of the over-the-counter market has not yet formed. Zhang Sen (2018) believes that the NEEQ is of great significance to SMEs. The NEEQ can not only solve the problem of corporate financing difficulties, but companies can also improve their own management systems and increase the level of information disclosure by listing on the NEEQ, which will provide follow-up development. power. [6] Liu Lizhen (2018) believes that more attention should be paid to the design of the transfer mechanism to optimize the resource allocation of enterprises. [7] Zhang Chuchen (2018) believes that the NEEQ provides a platform for direct financing of SMEs, which is conducive to broadening corporate financing channels. [8] Tian He Muyuan (2017) pointed out that after companies are listed on the NEEQ, the transparency will increase and the market has a fair pricing basis for them. Companies can raise funds through private placement or equity pledges. [9] Liu Huiming (2017) proposed the importance of establishing a transfer mechanism. The transfer mechanism can not only improve the liquidity of the NEEQ companies, but also increase the exit methods for the venture capital of small and medium-sized enterprises. [10] Guo Encai (2016) pointed out that if a company wants to achieve real value enhancement in the NEEQ market, it must start with its own development and focus on the improvement of its own strength. [11]

\subsection{Equity pledge financing issues}

Liu Linxuan (2014) believes that due to the strong equity liquidity, equity pledges are easily accepted by pledgers and can broaden the company's financing channels. However, the company's value will be largely affected by equity pledges and decrease. Pay attention to weighing the risks and benefits when making equity pledges. [12] Huang Changgan (2015) believes that equity pledges have their own advantages for different entities. For enterprises, equity pledges have lower risks and higher efficiency, which can help enterprises raise funds at a faster rate. As far as banks are concerned, due to the liquidity of equity, they can reduce the risk of bad and bad debts. [13] Cao Miao (2015) analyzed from the perspective of different shareholders, and believed that equity pledge is extremely beneficial to major shareholders. It can not only obtain cash flow, but also maintain the controlling equity of major shareholders, but the equity pledge involves the risk of leverage and the risk of transfer of control rights may damage the rights and interests of minority shareholders and exacerbate conflicts of interest among shareholders. [14] 


\section{CASE INTRODUCTION}

\subsection{Basic situation of the company}

\subsubsection{Case company selection}

First, Xinwei Technology has the typical characteristics of most NEEQ companies: high growth and more restricted stocks (the proportion of restricted stocks is $52.73 \%$ ), so the company is used as a research object for NEEQ companies Have a certain degree of representativeness.

Second, Xinwei Technology has conducted multiple equity pledges before and after, which is consistent with the development path of China's NEEQ market. Through comparison, it can be reflected that with the continuous development of the NEEQ market, the company's pricing foundation has been continuously improved, and the value of shares has gained more Recognition.

Third, Xinwei Technology's financing methods are mainly private placement and equity pledges. The basis for selection is mainly based on the company's development stage, and it maintains a good debt-to-asset ratio while expanding the scale of development. For other seekers of funds. The NEEQ enterprises have certain reference significance

\subsubsection{Company development status}

Kaifeng Xinwei Electronic Technology Co., Ltd. was registered and established in the Free Trade Zone Service Center of Kaifeng Market Supervision Administration on February 17, 2011, with a registered capital of 60,654,01 million. Mao Wei, a natural person, is the chairman of the company and is the company's controlling shareholder and the actual controller, currently holds 28.138 million shares, accounting for $46.39 \%$ of the share capital.

Xinwei Technology was listed on the NEEQ on April 1, 2015, with the stock code of 832230, and the lead broker is Guodu Securities, and it currently ranks among the entrepreneurial layers of the NEEQ.

\subsection{Company Financing}

The company has conducted 12 equity pledges and 3 private placements since its listing. All the abovementioned equity pledges did not adversely affect the company's equity structure, nor did it affect the company's normal operations and shareholders' rights. It was listed on the NEEQ. Later, with the improvement of the company's management system and the effective disclosure of information, the liquidity of its shares has increased significantly, the market has a fair recognition of stocks, and the pricing basis has been improved. As a result, the company can borrow more funds through equity pledges and ease liquidity pressure

\section{CASE ANALYSIS}

\subsection{Feasibility analysis of equity pledge of Xinwei Technology}

\subsubsection{Endogenous financing}

Endogenous financing refers to the use of funds accumulated in the company's business activities to convert them into investment, which has the advantages of low financing costs and high autonomy and flexibility. Xinwei Technology's net profits from 2014 to 2017 were $531,200,-1.201,300,14.190,300$, and 17.7759 million. Although these profits can be used as sources of internal financing, the scale of funds is limited, and the company is in the development stage, and the profits are also Unstable, so endogenous financing can only be used as a supplement

\subsubsection{Company development status}

\subsubsection{Equity financing.}

\section{Turning board}

After the listing of Xinwei Technology, the development status is relatively unstable, the retained profit fluctuates greatly, and it does not meet the listing requirements for the time being, and the time cost and risk level of the IPO are both high. These transfer costs are important for Xinwei that is still in the growth stage. In terms of technology, the burden is greater. Therefore, the company is less likely to raise funds through transfers in the short term.

\section{Private placement of equity}

Since its listing, Xinwei Technology has only conducted three private issuances. It can be found that the fixed increase has the following problems in actual use: First, it may lead to the dispersion of the company's equity and dilute the control of the company. Second, the monetary cost and time cost of the fixed increase are relatively high. The fixed increase involves the intermediary fees of securities firms and accounting firms. In addition, the board of directors must review and approve the securities regulatory commission before the fixed increase. Filing and registration and making status reports have a long issuance cycle. Third, companies need to face the risk of failure to issue. Fourth, the use of funds is subject to the supervision of the host brokerage and the share transfer system, and the use of funds is not flexible. 


\subsubsection{Debt Financing}

\section{Bond financing}

Xinwei Technology has not adopted bond financing methods, mainly because Xinwei Technology has failed to meet the standards for issuing corporate bonds and corporate bonds. This type of financing method has complicated application procedures and strict approvals, and has strict requirements on the company's financial status. It is suitable for mature enterprises such as stateowned enterprises or listed companies. As a small and medium-sized enterprise, Xinwei Technology is less likely to succeed in financing through the issuance of bonds.

\section{Bank loans}

Traditional bank loans require real estate as collateral. When the loan cannot be repaid, the bank will sell the mortgaged real estate to repay the debt. At that time, the company will lose the production basis on which it depends and face the risk of bankruptcy. Secondly, traditional bank loans need to go through a complicated review process, and the price of fixed assets must be reviewed by a specialized agency. The process is more complicated. As a small and mediumsized enterprise, Xinwei Technology generally obtains a small loan amount and a short term.

\section{Equity pledge financing}

From a company perspective, equity pledge financing has the following advantages:

First, make full use of restricted shares. After the company is listed on the New OTC Market, the company owns a large portion of restricted stocks. This part of the stock has poor liquidity, which restricts the company's equity transactions. The use of restricted stocks for equity pledge has improved the liquidity of this part of the stock and greatly increased the funds.

Second, the company has a high degree of freedom in the use of funds. The company can use equity pledge financing to make up for its capital needs according to its own circumstances, and the scope of the use of funds does not exceed the scope of the contract, and there are no too many restrictions.

Third, the procedure is simple and the efficiency of fund-raising is high. Equity pledge only requires both parties to reach an agreement and go through the pledge registration, which can raise more funds in a relatively short period of time.

Fourth, it can guarantee the company's control and shareholding structure. In addition to restricting free transfer, the equity used for pledge will not have much impact on the rights of shareholders. Shareholders can better manage the company on the basis of obtaining capital and ensuring control.
In addition, banks and other financial institutions actively participate in equity pledges because of the benefits they bring. Compared with traditional mortgage loans, the pledged equity is more liquid than the mortgaged real assets. Financial institutions can quickly realize cash when risks occur. In addition, financial institutions will also charge a certain amount of interest to the pledger to guarantee themselves. As result, financial institutions such as banks and securities companies have assumed lower risks while guaranteeing a normal rate of return, and are happy to pledge equity with small and medium-sized enterprises.

\subsection{Analysis of the rationality of Xinwei Technology's equity pledge}

China's "Guarantee Law" stipulates that only equities that can be transferred in accordance with the law can be used for pledge. The NEEQ corporate stocks have their particularities. Not all stocks are freely transferable, and there are some restricted tradable shares. According to the "Guidelines for the Registration of PROP Securities Pledge for Investors of China Clearing Shanghai Branch", when the restricted tradable shares are pledged as pledges, they shall not be transferred during the restricted sale period. It can be seen that the restricted shares can be freely transferred after meeting certain conditions. Therefore, the shares of NEEQ companies can be pledged. In the case of this article, all the equity pledged by Xinwei Technology are restricted circulation shares, which does not affect its legitimacy.

\subsection{Analysis of the effect of the equity pledge of Xinwei Technology}

\subsubsection{Analysis of solvency}

The high current ratio in 2015 was due to the fact that fixed assets entered the renewal period, and the number of scraps was higher than in previous years, resulting in large changes in fixed asset projects and an increase in the proportion of current assets. The significant increase in the interest protection multiple in 2016 was due to the large amount of external financing obtained in 2016, coupled with the acquisition of Tongfeng Real Estate and the consolidation of financial statements, and the profit of Tongfeng Real Estate was RMB 6,826,700, which resulted in a substantial increase in the company's profit.

\subsubsection{Profitability analysis}

The company's operating income is increasing year by year, but the gross profit margin is decreasing. This is mainly due to the increase in the salaries of the project personnel and the increase in the commission ratio, which increases the personnel costs. However, the 
company's revenue corresponds to the number of agency fee points contracted with the developer. The upward adjustment has caused the company's overall gross profit margin to drop significantly. The reason for the negative net profit in 2015 was mainly due to the downturn in the real estate industry, the decrease in sales staff's business volume, and the decrease in income, and the company also incurred more expenses to prepare for the NEEQ listing. In addition, from the perspective of the company's net profit, it can be known that the company has been in a growth stage in recent years, and the funds obtained by the equity pledge effectively ensure the company's growth process.

\subsubsection{Cashflow analysis}

The development of the company's business has increased a large number of employees and the increase in employee compensation, which has significantly increased the cash flow indicated by operating activities, and the amount of investment has also continued to increase; as for the increase in the net cash flow of financing activities, it is due to the company's equity Pledge loans ensure the daily liquidity needs.

\subsubsection{Analysis of growth ability}

The 2015 data was due to the general background at the time, the entire real estate industry was in a downturn, and the company also participated in the NEEQ listing and major asset restructuring matters, which led to a decline in the data. After being listed in 2015, the company has achieved explosive growth.

In summary, equity pledge financing can solve the short-term liquidity shortage of Xinwei Technology, encourage shareholders to better manage the company, increase the possibility of repaying loans, improve the efficiency of capital utilization, and also meet the temporary funds of growing companies. Shortage.

\subsection{5. $Z$ value analysis}

Here the $\mathrm{Z}$ value is defined as:

$$
Z=1.2 X_{1}+1.4 X_{2}+3.3 X_{3}+0.6 X_{4}+0.999 X_{5}
$$

Table $1 \mathrm{Z}$ value analysis

\begin{tabular}{|l|c|c|c|}
\hline \multicolumn{1}{|c|}{ Year } & $\mathbf{2 0 1 6}$ & $\mathbf{2 0 1 7}$ & $\mathbf{2 0 1 8}$ \\
\hline Z score & 1.4216 & 1.9911 & 2.1965 \\
\hline $\begin{array}{l}\text { Z value increased and } \\
\text { decreased year-on- } \\
\text { year }\end{array}$ & -- & 0.4007 & 0.1031 \\
\hline \multicolumn{3}{|c|}{ Factor decomposition } & 0.2237 \\
\hline $\begin{array}{l}\mathrm{X}_{1}=\text { Working } \\
\text { capital/total assets }\end{array}$ & -0.0412 & 0.1873 & 0.1569 \\
\hline $\begin{array}{l}\mathrm{X}_{2}=\text { Retained } \\
\text { earnings/total assets }\end{array}$ & 0.8997 & 0.1250 & 0.0374 \\
\hline $\begin{array}{l}\mathrm{X}_{3}=\text { EBIT/Total } \\
\text { Assets }\end{array}$ & 0.1260 & 0.1038 & 2.0017 \\
\hline $\begin{array}{l}\mathrm{X}_{4}=\text { Total } \\
\text { stockholders' equity } \\
\text { (including minority) } \\
\text { total market } \\
\text { value/total liabilities } \\
\text { on the day }\end{array}$ & 0.9254 & 1.4608 & Unstable \\
\hline $\begin{array}{l}X_{5}=\text { Operating } \\
\text { income/total assets }\end{array}$ & 0.3744 & 0.3729 & Unstable \\
\hline $\mathbf{Z}$ value results & Worrying & & 0.3784 \\
\hline
\end{tabular}

When the $\bar{Z}$ value is less than 1.81 , it means the company's current financial situation is worrying; when $1.81 \leqslant \bar{Z} \leqslant 2.675$, it means the company's current financial situation is unstable; when the $\bar{Z}>2.675$, which means the company's current financial situation is good. 
Compared with 2016, the $\bar{Z}$ value in 2017 and 2018 has increased due to: (1) The difference between the company's current assets and current liabilities has decreased, equity pledge financing has increased, shortterm borrowings have decreased, and therefore working capital has increased; (2) In terms of the value of $X_{4}$, the change in shareholder equity in 2016 compared with 2017 is not obvious, mainly due to the increase in $X_{4}$ due to the decrease in liabilities, especially the decrease in current liabilities, which led to the decrease in total liabilities. This indicator changed in 2018 The year is more significant.

In summary, through the analysis of the $\bar{Z}$ value, Xinwei Technology's overall financial situation is not very good, but the situation is gradually improving.

\subsection{Analysis of risk of equity pledge of Xinwei technology company}

\subsubsection{Risks of changes in equity value}

Equity is different from ordinary fixed assets and other pledges. It has the characteristics of high volatility, and its volatility is affected by the company's development status, market environment and its own liquidity. When the stock price drops to a threat to the rights of the pledgee, the pledgee has the right to auction the equity to recover the loan. In this case, due to the mentality of chasing ups and downs, the stock price is often lower than its own value level. Therefore, when the company's stock price declines significantly, the company should replenish the margin or add pledge in time to avoid liquidation.

In recent years, the company's operating income and net profit have increased significantly, and gross profit margins have been declining. Therefore, more attention should be paid to fluctuations in stock prices.

\subsubsection{Moral hazard}

The pledge of major shareholders' equity allows major shareholders to obtain cash flow while avoiding the weakening of control rights. In this case, it is likely to cause moral hazard, because major shareholders enjoy control of the company, but transfer the risk of equity depreciation to With regard to the pledgee, in the case of information asymmetry, major shareholders may take actions such as hollowing out the company for personal interests and harm the interests of the company, thereby harming the interests of the pledgee.

After Xinwei Technology was listed on the NEEQ, information asymmetry has been greatly improved. From the perspective of profit indicators and growth indicators, after Xinwei Technology was listed and successfully obtained financing, the level of corporate standardization has been significantly improved, and the operating capability has increased significantly. Competitiveness continues to increase.

\section{CONCLUSION}

As a typical representative of NEEQ companies, Xinwei Technology has adopted a multi-channel financing method and used equity pledges to solve short-term liquidity shortages, and has achieved remarkable results. Many of the pledged loans of the company have been repaid on time. It has accumulated a good reputation for the company.

In summary, equity pledge financing is very suitable for NEEQ companies that have many restricted stocks and hope to retain control of the company. It has the characteristics of high degree of freedom of capital use and low financing costs. However, you cannot rely too much on equity pledge financing, and you should always be alert to short-term loans and long-term investments.

In response to the above research conclusions, the following suggestions are put forward.

Encourage securities companies to carry out equity pledge financing

Compared with other financial institutions, the sponsoring securities firms of the NEEQ companies have more information advantages and have more insight into the fluctuations of stock prices. Therefore, it can encourage more securities firms to participate in equity pledge financing, which can increase the company The source of funds can bring new business to the securities company.

Pay attention to protecting the interests of the pledgee

Equity itself has a certain risk of price fluctuations, so equity pledges with equity as a pledge inevitably have certain risks. However, because the pledgee is in a relatively weak position in terms of information, it is impossible to conduct timely information on changes within the company. Effective understanding cannot accurately estimate the value of equity. Therefore, in order to protect the interests of the pledgee, the pledger can be required to disclose necessary information, and timely disclosure of changes that do not involve the company's business secrets but will affect the value of equity.

\section{Explore new ways to diversify the risks of equity pledge financing}

Insurance companies can withdraw from the insurance business related to equity pledges, and can provide customized services for the equity pledges of NEEQ companies. In addition, professional intermediaries can investigate companies applying for equity pledge financing and provide professional advice 
to the pledgee. During the period of equity pledge financing, professional intermediaries can continuously supervise the company and provide timely feedback to the pledgee. The participation of the professional intermediary structure reduces the information cost of the pledgee to a certain extent, and the insurance products of insurance institutions can also share part of the equity pledge financing risk.

\section{Improve the construction of the NEEQ market}

Equity pledge financing has a direct and close relationship with the value of equity, and liquidity is a prerequisite for equity pledge. The author believes that this situation can be improved through the development of a mixed trading system. The liberalization of market maker qualifications can break the market-making monopoly to a certain extent, form a competitive advantage, increase the supply of market-making services on the NEEQ, and at the same time bidding transaction information transparency can form a more reasonable valuation.

\section{REFERENCES}

[1] Chen Can. Analysis of the NEEQ corporate equity pledge financing [D]. Southwestern University of Finance and Economics, 2016.

[2] Liu Quanyue. Analysis of the NEEQ corporate equity pledge financing [D]. Soochow University, 2017.

[3] Zhang Nan. Analysis of the reasons and effects of equity pledge financing of enterprises on the NEEQ [D]. Inner Mongolia University of Finance and Economics, 2018.

[4] Gao Mingzhe. Research on the Financing Issues of NEEQ Enterprises[D]. Soochow University, 2016.
[5] Di Weikai. Risk analysis of equity pledge financing in the New OTC Market [D]. Hebei University, 2018.

[6] Zhang Sen. Analysis of the financing efficiency of the NEEQ enterprises[J]. Financial Economics, 2018(14): 126-127.

[7] Liu Lizhen. Discussion on the financing of small and medium-sized enterprises in the NEEQ market[J]. Economic Research Guide, 2018(17):161-165.

[8] Zhang Chuchen. Research on the status quo and countermeasures of the "NEEQ" market development[J]. Times Finance, 2018(26):186-188.

[9] He Muyuan, Zhang Yun. The rise, development and prospects of China's NEEQ market[J]. Quantitative Economics and Technical Economics Research, 2017, 34(04): 74-91.

[10] Liu Huiming. Analysis and Suggestions on the Status Quo of Fixed Growth of Enterprises on the NEEQ [N]. Securities Daily, 2017-07-08 (A03).

[11] Guo Encai. "The NEEQ" recreates a puzzle to see through [D]. China High-tech Zone, 2016.

[12] Liu Linxuan. The cost and benefit of listing on the NEEQ and SMEs[D]. Accountant, 2014.

[13] Huang Changgan. How to make fixed increase financing after the company's "NEEQ" is listed? [D]. Guangdong Legal System Shengbang Law Firm, 2015.

[14] Cao Miao. Research on the Financing Efficiency and Influencing Factors of China's NEEQ Enterprises [D]. South China University of Technology, 2015. 